University of Wollongong

Research Online

Faculty of Engineering and Information

Faculty of Engineering and Information

Sciences - Papers: Part A

Sciences

$1-1-2015$

Direct power control of DFIG based wind turbine based on wind speed estimation and particle swarm optimization

Mehrdad Tarafdar Hagh

University of Tabriz, haque1347@yahoo.com

S Roozbehani

University Of Tabriz,

F Najaty

University Of Tabriz,

S Ghaemi

University Of Tabriz,

Yingjie Tan

University of Wollongong, yt816@uowmail.edu.au

See next page for additional authors

Follow this and additional works at: https://ro.uow.edu.au/eispapers

Part of the Engineering Commons, and the Science and Technology Studies Commons

Research Online is the open access institutional repository for the University of Wollongong. For further information contact the UOW Library: research-pubs@uow.edu.au 


\title{
Direct power control of DFIG based wind turbine based on wind speed estimation and particle swarm optimization
}

\author{
Abstract \\ This paper presents a direct power control (DPC) design of a grid connected doubly fed induction \\ generator (DFIG) based wind turbine system in order to track maximum absorbable power in different \\ wind speeds. A generalized regression neural network (GRNN) is used to estimate wind speed and \\ thereby the maximum absorbable power is determined online as a function of wind speed. Finally the \\ proposed DPC strategy employs a nonlinear robust sliding mode control (SMC) scheme to calculate the \\ required rotor control voltage directly. The concept of sliding mode control is incorporated into particle \\ swarm optimization (PSO) to determine inertial weights. The new DPC based on SMC-PSO scheme has \\ acceptable harmonic spectra of stator current by using space vector modulation (SVM) block with \\ constant switching frequency. Simulation results on 660-kw grid-connected DFIG are provided and show \\ the effectiveness of the new technique, for tracking maximum power in presence machine parameters \\ variation.

\section{Keywords} \\ control, estimation, optimization, swarm, power, direct, speed, turbine, wind, dfig, particle \\ Disciplines \\ Engineering | Science and Technology Studies

\section{Publication Details} \\ M. Tarafdar Hagh, S. Roozbehani, F. Najaty, S. Ghaemi, Y. Tan \& K. M. Muttaqi, "Direct power control of \\ DFIG based wind turbine based on wind speed estimation and particle swarm optimization," in Power \\ Engineering Conference (AUPEC), 2015 Australasian Universities, 2015, pp. 1-6.
}

\section{Authors}

Mehrdad Tarafdar Hagh, S Roozbehani, F Najaty, S Ghaemi, Yingjie Tan, and Kashem M. Muttaqi 


\section{Direct Power Control of DFIG based Wind Turbine based on Wind Speed Estimation and Particle Swarm Optimization}

\author{
M. T. Hagh, S. Roozbehani, F. Najaty, S. Ghaemi \\ Faculty of Electrical and Computer Engineering \\ University of Tabriz, Iran
}

\author{
Y. Tan, K. M. Muttaqi \\ School of Electrical, Computer and Telecom. \\ University of Wollongong, Australia
}

\begin{abstract}
This paper presents a direct power control (DPC) design of a grid connected doubly fed induction generator (DFIG) based wind turbine system in order to track maximum absorbable power in different wind speeds. A generalized regression neural network (GRNN) is used to estimate wind speed and thereby the maximum absorbable power is determined online as a function of wind speed. Finally the proposed DPC strategy employs a nonlinear robust sliding mode control (SMC) scheme to calculate the required rotor control voltage directly. The concept of sliding mode control is incorporated into particle swarm optimization (PSO) to determine inertial weights. The new DPC based on SMC-PSO scheme has acceptable harmonic spectra of stator current by using space vector modulation (SVM) block with constant switching frequency. Simulation results on $660-\mathrm{kw}$ gridconnected DFIG are provided and show the effectiveness of the new technique, for tracking maximum power in presence machine parameters variation.
\end{abstract}

Keywords-Wind Turbine, DFIG, MPPT, Neural Network, SMC, PSO.

\section{INTRODUCTION}

Using renewable energy for different applications has salient growth in recent years. Among renewable energies, wind energy has attracted more attention since 1991. Installation capacity of wind turbine was 31.1 GW in 2002, and this capacity reached to $370 \mathrm{GW}$ by the end of the year 2014[1].Variable speed wind turbines are commonly equipped with DFIG. In fact, DFIGs are wound rotor induction generators with their stators connected to grid directly and their rotors connected to grid through a back to back power electronic converters. The grid side converter controls the power exchange between the DC link and the grid while controlling the DC link voltage amplitude. The rotor side converter is responsible for the adjustment of the desired active and reactive power from DFIG based wind turbine system. It is well known that the power delivered by wind turbines which are directly coupled with grid is not constant due to the wind variability. However, in spite of sudden wind speed variations, wind turbine generators should normally be capable of determining and extracting maximum possible mechanical power from the wind and converting it into electrical power. This study focuses on two aspects of wind turbine. First aspect is to determine the maximum power under vriable wind speed and second aspect is the power control design of DFIG for maximum power point tracking (MPPT).

In first aspect, for each wind speed, a particular turbine rotation speed is desired to deliver the maximum active power generated by the wind turbine to the grid. Identification of the desired rotation speed can be done through two approaches. In first approach, the wind speed is measured by anemometer and then this value determines the optimal desired shaft speed. These mechanical sensors (anemometer) increase the cost and reduce the reliability of overall wind turbine system. Contrarily, in second approach, sensorless methods have been introduced to estimate wind speed. In [2] the wind speed is estimated with an artificial neural network and then the optimum turbine rotation speed is determined for each instantaneous estimated wind speed. Finally speed controller operates in a way that the DFIG can track the optimal rotation shaft speed. In this paper, the GRNN is used to estimate wind speed and thereby the maximum absorbable power is determined online as a function of wind speed.

In second aspect, in [3]-[4], stator flux oriented vector control (VC) is applied, and the active and reactive output powers of DFIG are controlled independently by regulating the decoupled rotor currents. The main drawback of the control algorithm in [3] and [4] is that they use PI controllers for implementing stator flux oriented $\mathrm{VC}$ and therefore their performance depends highly on accurate machine parameters such as stator resistance, rotor resistance, and inductances. In [5], an application of neural networks in vector control in DFIG based wind power system is presented. Apart fromthe classic VC scheme, additional outer control loop for active and reactive powers are required to generate the reference values of $\mathrm{d}$ and $\mathrm{q}$ axis rotor currents. Direct torque control 
(DTC), as an alternative to the $\mathrm{VC}$ for induction machines, was proposed in [6],[7]. The DTC strategy provides direct regulation of machine's torque, and reduces the complexity of the $\mathrm{VC}$ strategy while minimizing the use of machine parameters. The DPC of DFIG stems from DTC in AC electrical drive [8]-[9]. The active and reactive stator powers calculated from measured voltages and currents are controlled by hysteresis regulator. Finally, the voltage vectors are selected from an optimal switching table based on outputs of the hysteresis regulators and the stator voltage or stator flux position. One main problem of [8]-[9] is that the converter switching frequency varies significantly with active and reactive power variations. The variable switching frequency makes the power converter and the $\mathrm{AC}$ harmonic filter complicated and expensive.

The design principles of SMC and its application to electrical drive were initially proposed in [10]. The SMC is used in wind and marine turbine driven by DFIG for improving the robustness of controllers [11][12]. In [11]-[12], outer control loops are needed to provide the reference values of rotor current components for controlling active and reactive powers.

In order to solve the drawback highlighted above, this study proposes a new DPC strategy that employs a nonlinear robust sliding mode control (SMC) scheme to directly calculate the required rotor control voltage. One of the main features of the proposed controller is that it does nt need any outer control loop to generate reference rotor current components. The concept of sliding mode control is incorporated into particle swarm optimization (PSO) to determine inertial weights. In [13], these weights are determined through try and error. The results of this paper were compared with [13] - The new DPC based on SMC-PSO scheme has acceptable harmonic spectra in the stator current by using space vector modulation block with constant switching frequency.

The rest part of the paper is organized as follows. In part II, the wind speed estimation algorithm is presented and then a similar approach used in [13] is used for determining maximum power in variable wind speeds. In parts III and IV, control strategy design and simulation results are obtained in MATLAB/Simulink.

\section{Proposed AlgorithM FOR DETERMINING THE MAXimum Absorbable PoWer of Wind Turbine}

The mechanical power extracted from the wind can be expressed as [3]:

$$
P_{m}=\frac{1}{2} \pi R^{2} \rho C_{P}(\lambda, \beta) v^{3}
$$

where $R, \rho, C_{P}$ and $v$ correspond to the radius of the turbine propeller, the air density, power coefficient and wind speed, respectively. $C_{P}$ is a nonlinear function of tip speed ratio $\lambda$ and the pitch angle $\beta . \lambda$ is given by:

$$
\lambda=\frac{R \omega_{t}}{v}
$$

where $\omega_{t}$ is the rotational speed of the wind turbine. According to (1), the maximum value of power is determined as function of optimum tip speed ratio $\lambda_{\text {opt }}$. The value of pitch angle $\beta$ is set to zero for maximum power capture. With this method, the value of tip speed ratio should be measured. If this value is $\lambda_{\text {opt }}$, it means the wind turbine is delivering the maximum power to grid. Otherwise, the value of reference power must be changed using the following equation [3]:

$$
\begin{aligned}
& P_{\text {nref }}(t+1)=P_{\text {nref }}(t) \pm T_{1}\left(1-\exp \left(-T_{2} \mid \text { error } \mid\right)\right) \\
& \text { error }=\lambda-\lambda_{\text {opt }}
\end{aligned}
$$

where $T_{1}$ and $T_{2}$ are optimized and are constants in (3). $P_{\text {nref }}(t+1)$ and $P_{\text {nref }}(t)$ are the maximum absorbable power of wind turbine at moments of $t$ and $t+1$ respectively. The limitation of (3) is the measurement ofof tip speed ratio. According to (2), the value of wind speed and rotational speed of the wind turbine should be measured to determine the value of tip speed ratio. The rotor speed is determined by some well known machine calculation[13]. This paper uses GRNN [14] for estimating wind speed. The GRNN is a kind of radial basis function (RBF) network that is often used for function approximation. The overall input-output mapping for the GRNN is given by:

$$
\hat{v}(i, j)=b+\sum_{i=1}^{m} \sum_{j=1}^{n} w_{i j} \exp \left(-\left\|z-C_{i j}\right\|^{2}\right)
$$

where $\mathrm{z}=\left[\mathrm{p}_{\mathrm{m}} \mathrm{W}_{\mathrm{m}}\right]$ is the input vector, $C_{i j}$ is the center of the $j$ th RBF units in the hidden layer, $n$ is the number of RBF units, $b$ and $w_{i j}$ are the bias term and the weight between hidden and output layers respectively, and $\hat{v}$ is the output of the GRNN that represents the estimated wind speed. The GRNN in fig. 1 is trained offline using a training data set that covers the entire operating range of the wind turbine. The entire training data set is created by combining all the data samples of rotational speed, mechanical power and wind speed:

$$
\begin{aligned}
& \bar{Z}=\left[\omega_{m}(i), p_{m}(j) \mid i=1, \ldots, n ; j=1, \ldots, m\right] \\
& v=[v(i, j) \mid i=1, \ldots, n ; j=1, \ldots, m]
\end{aligned}
$$

where $m$ and $n$ are the numbers of data samples for generator rotor speed and mechanical power respectively. After determining the training data set, the parameters of the GRNN, i.e., the number of RBF units, the RBF centers, width, and the output weights, are 
calculated by offline training. These parameters are then fixed for online estimation of the wind speed. Since the training data set covers the entire operating range of the wind turbine, the resulting GRNN provides an accurate wind speed estimation model over the wind turbine operating range. The input of GRNN for the mechanical power can be approximated by the following equation:

$$
P_{m} \approx P_{e}+P_{\text {loss }}=\left(P_{s}+P_{r}\right)+P_{\text {loss }}
$$

where $P_{e}, P_{s}, P_{r}, P_{\text {loss }}$ are the electrical power, stator active power, rotor active power and total power loss of the wind turbine respectively. The method of estimation of the total losses in the wind turbine that include gearbox losses, the induction generator losses, the losses in the rotor side converter and the losses in the grid side converter are presented in [2].

\section{Direct Power CONTROL DeSign STRATEGy BASED ON SMC AND PSO:}

\section{A. Determine the reference active and reactive powers of stator:}

By considering the DFIG operation limit which is related to its P-Q curve [3] and as regards to (3), the reference active and reactive power that stator should track are given by:

$$
\left\{\begin{array}{l}
P_{r e f}=P_{n r e f}-P_{r} \\
Q_{r e f}=Q_{n r e f}-Q_{r}
\end{array}\right.
$$

where $P_{r}, Q_{r}$ are the active and reactive powers of the rotor and they are as following:

$$
\left\{\begin{array}{l}
P_{r}=\frac{3}{2}\left[u_{r d} i_{r d}+u_{r q} i_{r q}\right] \\
Q_{r}=\frac{3}{2}\left[u_{r q} i_{r d}-u_{r d} i_{r q}\right]
\end{array}\right.
$$

\section{B. Sliding Mode Controller Parameters Evaluated with PSO:}

The overall control structure of the system is shown in fig.2. Two sliding surfaces are defined by following equation :

$$
\left\{\begin{array}{l}
s_{1}(t)=y_{1}(t)-y_{1 r e f}(t)=P_{S}(t)-P_{r e f} \\
s_{2}(t)=y_{2}(t)-y_{2 r e f}(t)=Q_{S}(t)-Q_{r e f}
\end{array}\right.
$$

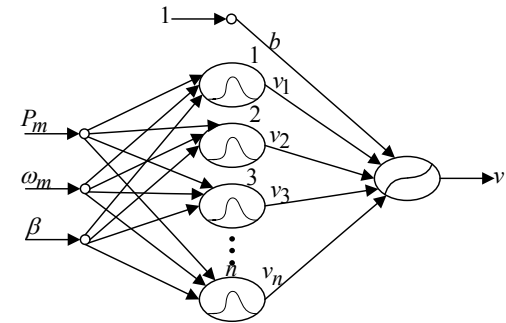

Fig. 1. The architecture of GRNN whose input and output vectors are mechanichal power, generator speed, and wind speed.

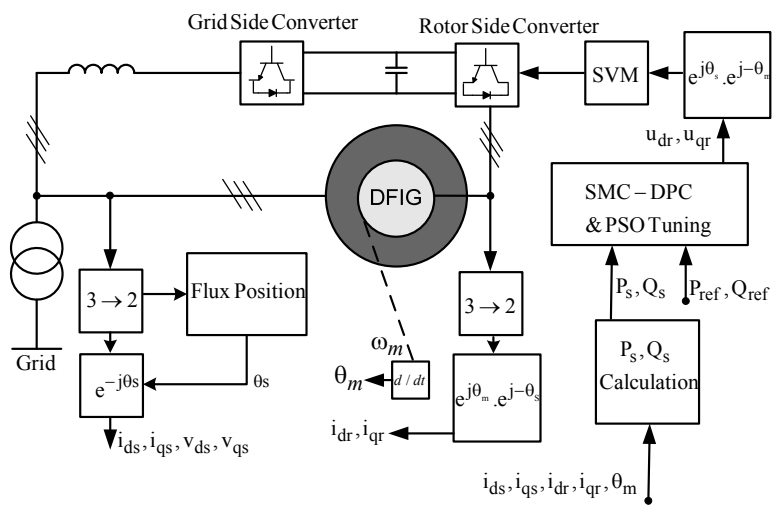

Fig. 2. Schematic diagram of the proposed SMC-based DPC tuning with PSO for a grid connected

Solving the Trajectory Tracking Problem withSMC leads to the reaching laws (11)[13]:

$u_{r}=\frac{-1}{\hat{G}_{\boldsymbol{r}}}\left[\hat{\boldsymbol{f}}^{*}(\boldsymbol{x})-\dot{\boldsymbol{y}}_{\boldsymbol{r e f}}+\boldsymbol{K} \operatorname{sgn}\left(\boldsymbol{S}_{\boldsymbol{i}}\right)\right]$

The input vector of $S V M$ unit in fig. 2 is determined through (11). Where $\hat{\boldsymbol{f}}^{*}(\boldsymbol{x})$ and $\hat{\boldsymbol{G}}_{\boldsymbol{r}}$ are related to DFIG model. Also:

$\operatorname{sgn}\left(s_{\boldsymbol{i}}\right)= \begin{cases}+1 & \text { if } s>0 \\ -1 & \text { if } s<0\end{cases}$

$\boldsymbol{K}=\left[\begin{array}{cc}\eta_{1}\left|s_{1}(t)\right|^{a_{1}} & 0 \\ 0 & \eta_{2}\left|s_{2}(t)\right|^{a_{2}}\end{array}\right]$

In [13], the parameters $\eta_{1}, \eta_{2}, a_{2}$ and $a_{2}$ are determined through experiments and have great impact on the performance of the controller. This paper is presented a method of choosing the parameters of the SMC using the PSO algorithm. The optimization algorithm is working off line. The concept of SMC is to maintain the state on the surface $s(t)=0_{2 \times 1}$ for all time. 
i.e., the criterion of $\boldsymbol{s}_{\boldsymbol{i}}(t)=0$ and $\dot{\boldsymbol{s}}_{\boldsymbol{i}}(t)=0$ should be satisfied. Therefore, a fitness function is defined as:

$$
f_{i}\left(s_{i}\right)=\sqrt{\frac{1}{N} \sum_{i=1}^{N}\left(\mathbf{s}_{i}^{2}+\dot{\boldsymbol{s}}_{i}^{2}\right)}
$$

where $f_{i}\left(s_{i}\right)$ denotes the $i$ th element in the fitness function vector. Also $N$ is the number of the surfaces; Therefore $N$ is equal to 2. The basic PSO operations used in this study are summarized as follows. The algorithm starts with $N$ particles. Each particle represents a candidate solution to the problem. Each particle in the search space has a current position $\left(l_{i}\right)$ and a current velocity $\left(v_{i}\right)$. The value of each particle is determined by fitness function $\left(f_{i}\left(\boldsymbol{s}_{i}\right)\right)$ Each particle moves on the cost surface with a velocity. The personal best position in the search space (localbest ${ }_{i}$ ) corresponds to the position where particle $i$ represents the best fitness function. The global best position in the search space (globalbest) represents the position yielding the best fitness function among all the $\left(\right.$ localbest $\left._{i}\right)$.This algorithm is defined as follows[15,16]:

$l_{i}^{n+1}=l_{i}^{n}+v_{i}^{n+1}$

$v_{i}^{n+1}=v_{i}^{n}+\rho_{1} \cdot r_{1} \cdot\left(l_{i}^{\text {localbest }}-l_{i}^{n}\right)+\rho_{2} \cdot r_{2} \cdot\left(l_{i}^{\text {globalbest }}-l_{i}^{n}\right)$

- Form initial population and initial velocities randomly.

- Calculate the value of each particle by fitness function.

- $\quad$ Find the local best of each particle.

- $\quad$ Find the global best of all the population.

- The PSO algorithm updates the velocity for each particle, then adds that velocity to the particle position or values. Velocity updates are influenced by both the best global solution associated with the lowest cost ever found by a particle and the best local solution associated with the lowest cost in the present population, according to (15) and (16). In these equations, superscript $\mathrm{n}+1$ denotes the $\mathrm{n}+1^{\text {th }}$ generation, and superscript $\mathrm{n}$ denotes the $\mathrm{n}$ th generation. Meanwhile, $\rho_{1}, \rho_{2}$ are the learning factors and $r_{1}, r_{2}$ are independent uniform random numbers. $l_{i}^{\text {localbest }}$ is the best local solution for the $\mathrm{i}^{\text {th }}$ particle and $l^{\text {localbest }}$ is the best global solution.

- Repeat the steps until the termination criteria are satisfied.

In (15), $l_{i}$ indicates control variables of matrix $\boldsymbol{K}_{\text {as }}$ shown in Table I. Also, the optimized parameters of $\boldsymbol{K}$ are shown in table I. The first row of this table is presented in [13] by using try and fault method and the second row of this table is found parameters of $\boldsymbol{K}$ by using PSO algorithm.

TABLE I. OPTIMIZED PARAMETERS OF $\boldsymbol{K}$

\begin{tabular}{|c|c|c|c|c|}
\hline METHOD & $\eta_{1}$ & $\eta_{2}$ & $a_{1}$ & $a_{2}$ \\
\hline PRESENTED IN [13] & 0.85 & 0.32 & 2.3 & 1.52 \\
\hline PSO & 0.852 & 0.32 & 2.2 & 1.54 \\
\hline
\end{tabular}

\section{Simulation Results}

In this section, the simulation results of proposed control strategy were performed in MATLAB/Simulink. The simulation step time is $0.001(\mathrm{sec})$. The parameters of $660 \mathrm{KW}$ wind turbine and DFIG are given in table II. The nominal converter dc-link voltage is set to $600 \mathrm{~V}$. The grid side converter has to maintain a constant dc-link voltage, and it is controlled by a method similar to the dc voltage controller in a PWM voltage source rectifier. Switching frequency of converter is set to $1 \mathrm{kHz}$ in SVM unites. Also, the method in [13] is used for estimating flux position $\left(\theta_{S}\right)$ as shown in fig.5.

\section{A. Simulation of actual and estimated wind speed}

In this paper the wind model is considered by combining steps and one Gaussian signal with the sample time and variance of 0.01 (sec) and 0.1 respectively. In fig.3, the wave forms of actual and estimated wind speed are shown. GRNN has been used for estimating wind speed. The results show that the estimated wind speed tracks the actual wind speed with

high accuracy.

\section{B. Simulation results of Proposed DPC}

With the estimated wind speed, the algorithms of sections III is used for determining the optimal desired power in each wind speed and finally is applied to wind turbine system. The waveforms of stator reference power, system response for tracking this power and active power of rotor are shown in fig.4. As shown in this figure, tracking error of the methods are acceptable and because of super synchronous operation of generator in $5(\mathrm{sec})$ to $10(\mathrm{sec})$, the sign of rotor active power is negative. This means that rotor is generating power in this condition.

The waveforms of reference reactive power of stator, system response for tracking this power and reactive power of rotor are shown in fig.5. Also the waveforms of generator speed, stator three-phase current, rotor three-phase current are shown in fig. 6 to 
fig.8, respectively. As regards to fig.6, the generator is operated in sub synchronous mode until $5(\mathrm{sec})$ and in $5(\mathrm{sec})$ to $10(\mathrm{sec})$ is operated in super synchronous mode.

\section{Response of MPPT}

The tip speed ratio is an important parameter for evaluating the response of MPPT. The wave form of tip speed ratio of wind turbine is shown in fig.9. As shown in this figure, this parameter is fluctuated around 8.1 which is the optimum value of tip speed ratio.

\section{Robustness of controller}

In this section the robustness of the controller for capturing maximum power is evaluated in presence of machine parameters variation. The machine parameters are changed in three patterns as shown in table II. As a result of implementing these patterns, the time responses of stator active power are shown in fig.10. As shown in this figure, the waveforms are matched, therefore the robustness of the controller is guaranteed. Also, if the tip speed ratio error is low, it is shown that the maximum power is generated and delivered to the electrical grid. As shown in this table the error value of tip speed ratio for proposed algorithm is lower in comparison with the method which is presented in [13].

\section{E. Evaluating THD of stator and rotor currents}

Harmonics spectra of stator and rotor currents are shown in fig.11 and fig.12, respectively when the average value of wind speed is $11 \mathrm{~m} / \mathrm{s}$. In this condition, the applied frequency to rotor is $18 \mathrm{~Hz}$. In fact, this is the slip frequency of rotor. Due to the use of SVM modulation technique and as regards to fig.10, the stator current has acceptable THD.

\section{CONCLUSION}

In this paper a new sensorless algorithm for determining maximum absorbable power in each wind speed has been proposed. Also, proposed direct power control employs sliding mode nonlinear controller to directly calculate the required rotor control voltage. The concept of sliding mode control is incorporated into particle swarm optimization (PSO) to determine inertial weights. The simulation results show the robustness of the algorithm and controller against changing machine parameters for capturing the maximum power. In addition, the new DPC based on SMC-PSO scheme has acceptable harmonic spectra of stator current by using space vector modulation (SVM) block with constant switching frequency. Some of the advantages of the proposed algorithm can be mentioned as learning capability, controllability through the reference power and low tip speed ratio error.

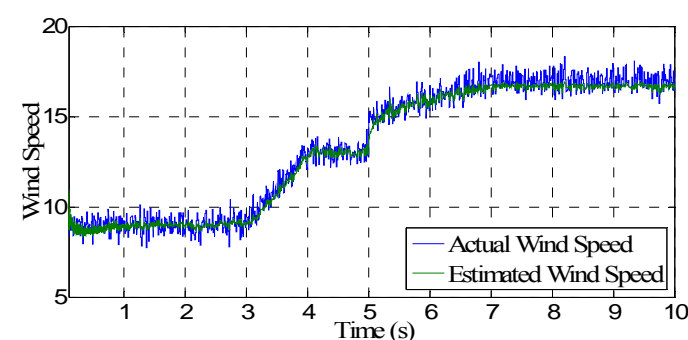

Fig. 3. Actual and estimated wind speed

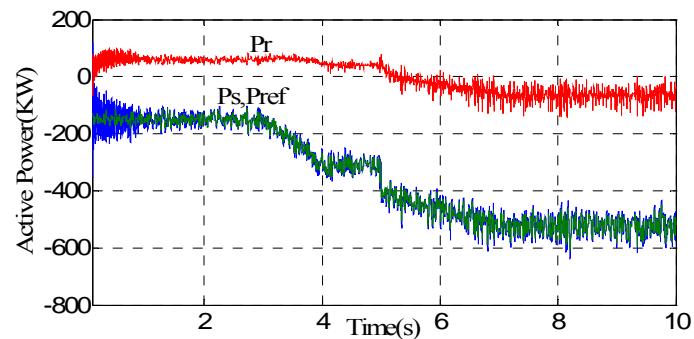

Fig. 4. Stator active power time response.in proposed SMC DPC \& PSO.

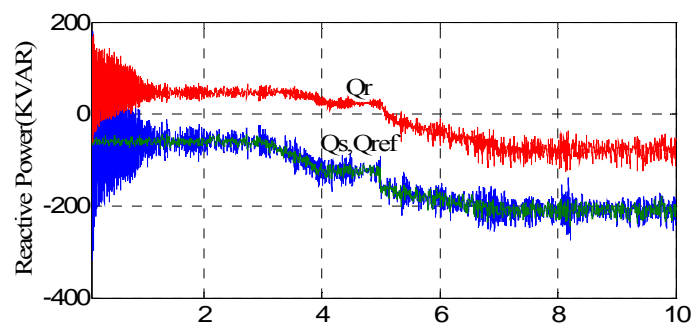

Fig. 5. Stator reactive power time response in proposed SMC DPC \& PSO.

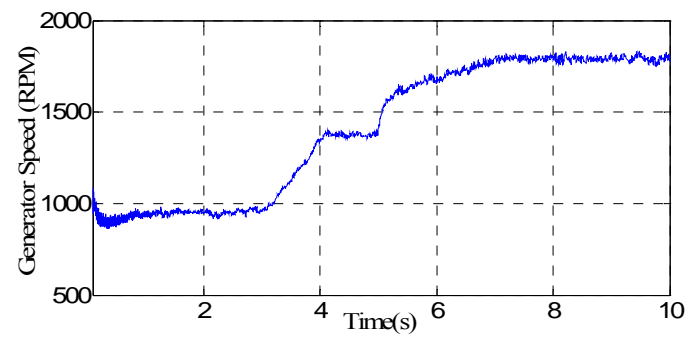

Fig. 6. Time response of generator speed

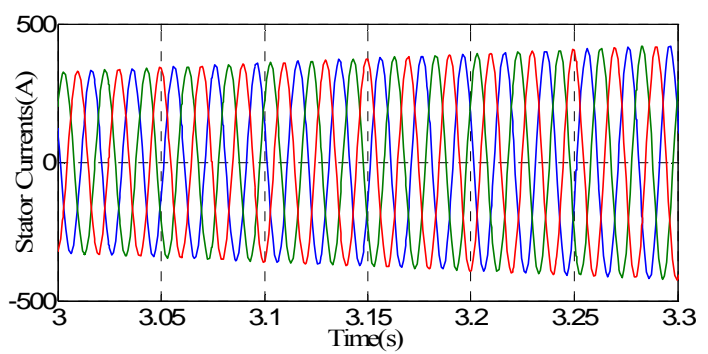

Fig. 7. Three phase stator currents in small time scale 


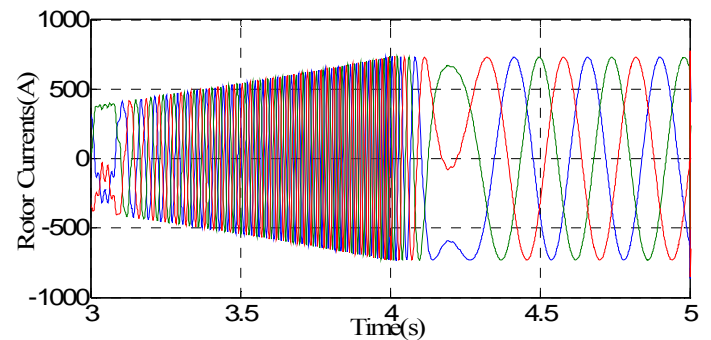

Fig. 8. Three phase rotor currents in small time scale

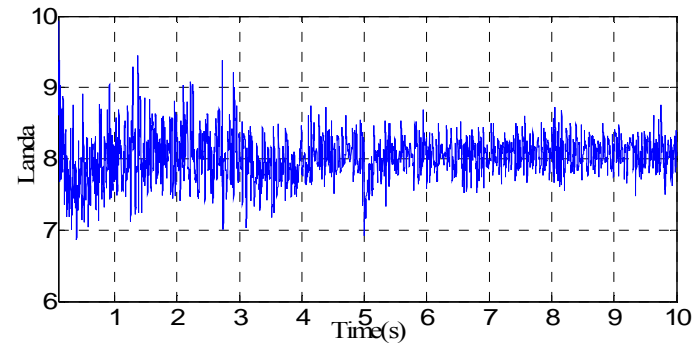

Fig. 9. Tip speed ratio of wind turbine

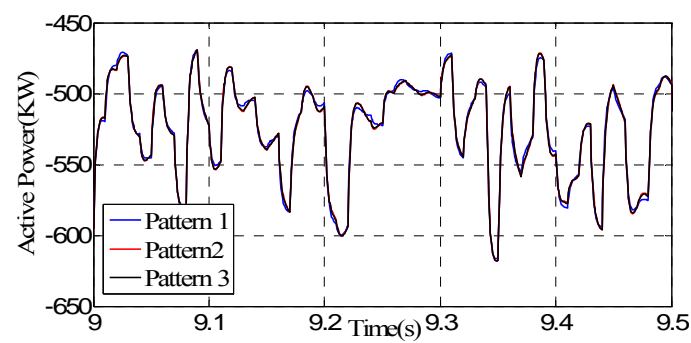

Fig. 10. Time response of stator active power as result of implementing patterns of tabl II.

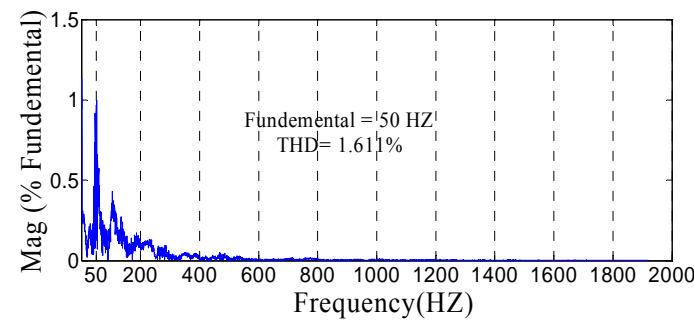

Fig. 11. Harmonics spectra of stator currents

TABLE II. ROBUSTNESS OF CONTROLLER

\begin{tabular}{|c|c|c|c|c|c|}
\hline \multicolumn{3}{|c|}{ DFIG parameters variation (\%) } & \multicolumn{2}{c|}{ Error of tip speed ratio } \\
\hline $\mathrm{R}_{\mathrm{r}}$ & $\mathrm{R}_{\mathrm{s}}$ & $\mathrm{L}_{\mathrm{r}}$ & $\mathrm{L}_{\mathrm{s}}$ & $\operatorname{Ref}[13]$ & PSO \\
\hline 0 & 0 & 0 & 0 & 0.0034 & 0.0029 \\
\hline 50 & 20 & 20 & 5 & 0.0036 & 0.0031 \\
\hline 100 & 100 & 5 & 5 & 0.0038 & 0.0032 \\
\hline $\operatorname{Rs}(\Omega)=6.5, \operatorname{Rr}(\Omega)=9, \mathrm{Ls}(\mathrm{mH})=.15, \mathrm{Lr}(\mathrm{mH})=.15$, \\
$\mathrm{Lm}(\mathrm{mH})=11$, Stator rated voltage $(\mathrm{V})=440$, \\
Frequency $(\mathrm{Hz})=50$, Pole pairs $=2$ \\
Generator rated power $(\mathrm{KW})=660$. \\
\hline
\end{tabular}

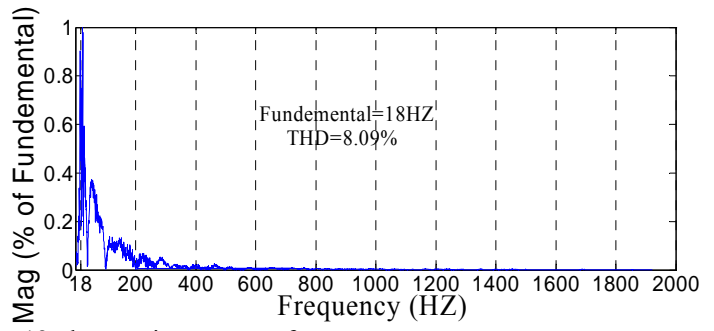

Fig. 12. harmonics spectra of rotor currents

\section{REFERENCES}

[1] World Wind Energy Association, Germany, [Online]. Available: http://www.wwindea.org

[2] W. Qiao, W. Zhou, J. M. Aller, and R. G. Harley, "Wind speed estimation based sensorless output maximization control for a wind turbine driving a DFIG," IEEE Trans. Power Electronics,vol.23, no.3;pp. 1156-1169, 2008.

[3] G. Tapia, A. Tapia, and J.X. Ostolaza, "Modeling and control of wind turbine driven by doubly fed induction generator," IEEE Trans. Energy Conversion, vol. 18,no.2, pp. 194-204, 2004.

[4] G. Tapia, A. Tapia, and J.X. Ostolaza, "Two alternative modeling approaches for the evaluation of wind farm active and reactive power performance," IEEE Trans. Energy Conversion, vol.21, no.4, pp. 0909-920, 2006.

[5] Orlando. s, Henrique. G, Antonio. M, Adriano. C, Nonlinear control of the doubly-fed induction generator in wind power systems, Renewable Energy, vol.35, pp.1662-1670, 2010.

[6] I. Takahashi and T. Noguchi, "A new quick-response and highfrequency control strategy of an induction motor," IEEE Trans. Ind. Appl., vol.22, no.5, pp.820-827, 1986.

[7] M. Depenbrock, "Direct self-control (DSC) of inverter-fed induction machine," IEEETrans. Power Electron,vol.4, pp.4204291988.

[8] Datta and V. T. Ranganthan, “ Direct power control of gridconnected wound rotor induction machine without position sensors," IEEE Trans. Power electron, vol.16, no.3, pp.390399, 2001.

[9] L. $\mathrm{Xu}$ and $\mathrm{P}$. Cartwright, "Direct active and reactive power control of DFIG for wind energy generation, IEEE Trans. Energy Convers, vol. 21, no.3, pp.750-758,2006.

[10] V.I.Utkin, Sliding Mode control design principles and applications to Electric drives, IEEE Trans.Ind .Electron, vol.40, no.1, pp.23-26, 1993.

[11] S. E. Ben Elghali, M. E. H. Benbouzid, T. Ahmad-Ali, J. F. Charpentier, and F. Mekri, "High-order sliding mode control of DFIG-based marine current turbine," in Proc.IEEE IECON, pp.1228-1233,2008.

[12] B. Beltran, T. Ahmad-Ali, and M. E. H. Benbozid," High order sliding mode control of DFIG-based wind turbine for power maximization and grid fault tolerance," in Proc. IEEE IEMDC,183-189. 2009.

[13] K. Abbaszadeh, S. roozbehani, a new method for capturing maximum power from wind turbine based on sliding mode control, journal of energy manegment, vol.1,num.2, 2012.

[14] S. Haykin, Neural Networks, Macmillan, New York, 1994.

[15] M. Tarafdar Hag, S. Galvani, "Minimization of Load Shelding by sequential use of Linear Programming and practical swarm optimization” Turk J Elec Eng \& Comp Sci, Vol.19, No.4, 2011.

[16] R.J. Wai, K.L. Chuang, J.D. Lee, “On line Supervisory Control Design for Maglev Transportation System via Total Sliding Mode Approach and Practical Sarm Optimization", IEEE. Trans.Automatic Control, Vol.55, No.7, 2010. 